be recorded when the fetus is still alive. The authors suggest that when the fetal circulation is failing there is likely to be a gradual reduction in the voltage of the fetal signal until the maternal rate rather than the fetal is recorded.

Though this alarming possibility is theoretically possible it has never been reported in the literature, nor have I cbserved it. Before jumping to a conclusion that might detract from the value of continuous monitoring of the fetal heart rate, it would be of considerable interest to find out through your columns whether any of your readers have had such a case which is well documented.-I am, etc.,

R. W. BEARD

Department of Obstetrics and Gynaecology,

St. Mary's Hospital Medical School,

1 Beard, R. W., Brudenell, J. M., Feroze, R. M., and Clayton, S. G., Fournal of Obstetrics and 78, 882 .

\section{Statistics and the M.R.C.P.}

SIR,-The Royal Colleges of Physicians of the United Kingdom are concerned at the apparent lack of acquaintance of many candidates for the diploma of M.R.C.P.(U.K.) with the principles of elementary statistics.

The extensive range of questions provided by Part I of the examination gives the candidate a good opportunity to demonstrate his understanding of the broad field of medicine, even if his knowledge of the various systems is somewhat uneven. However, understanding of the meaning, for instance, of standard deviation and a grasp of the significance of "P" and " $r$ " are essential in modern medicine.

The colleges therefore wish to bring to the notice of prospective candidates that particular attention may be given to statistics in future.-I am, etc.

J. F. STOKES Joint Examining Board Central M.R.C.P.(U.K.) Office, London $N . \mathbb{P} .1$.

\section{Postpartum Sterilization}

SIR,-Professor James Walker (1 September, p. 497) expresses regret that his opposite numbers in Birmingham have abandoned the practice of postpartum sterilization soon after delivery. In our experience, no matter how skilful the operator, any form of abdominal operation (laparotomy) may be an annoyance to the mother busy with her child. On occasion there may even be mild wound sepsis, or one may tend to blame the inevitable loss of ambulation for later thromboembolism. That is not to say that laparotomy carries some risk and laparascopic sterilization carries none. The instrument must be in the hands of an expert working with skilled anaesthetist.

Our group, having many years of experience of traditional postpartum sterilization, has come to prefer interval laparoscopic sterilization. The great advantage is that a puerperal laparotomy is avoided. Six weeks after delivery the mother returns for an overnight stay with or without her baby. She may return to her domestic and nursing duties in 24 hours.

We are quite sure that our colleagues in
Dundee put no pressure on their patients to accept sterilization. Nevertheless, a couple with a new baby may have second thoughts on sterilization; our policy of delay allows for this.-We are, etc.,

J. M. EMENS

J. A. JORDAN

Department of Obstetrics and Gynaecology,

Birmingham and

Midland Hospital for Women

Birmingham

\section{Think Again on Salmon}

SIR,-I was pleased to read your leadin article (27 October, p. 186) and heartily endorse your sugestion that the time has come to have another look at the Salmon proposals and how they are working. In Personal View (16 August 1969, p. 411) I expressed fears for the future and said, "Surely its wise from time to time to stop and think, and to take stock." I consider the time is overdue-the passing years have done nothing to allay these fears.

In the halcyon days before Salmon the nursing services were organized efficiently and economically by matrons and asssitan matrons-their offices were within the hospital and a better personal relationship thus obtained between the sisters and nurses. Important decisions could be made without the necessity of referring to a higher authority - number 9 or 10 . With the Salmon struc ture imposed upon us the picture has darkened. There are many more administrators in the name of nursing officers whose duties as a rule do not include nursing as such. The higher numbers sit in their respective offices, when they are not sitting in at endless meetings, removed from the patients and staff, and this tends towards a less personal relationship.

Can we then be surprised that so few senio nurses now wish to remain in the Health Service? In my view this is more and more becoming a service of administrators. The true nurse wishes to remain a practical nurse with clinical responsibilities to the patient, and when promotion comes, as come it should, does not want to be upgraded to a number removed from the bedside. This is the case at the present time with the ward sister, the most valuable member of the nursing team.

The increased cost to the Health Service of all this reorganization must be considerable, and it hardly appears to be a "best buy." With hindsight one wonders how the medical profession allowed the Salmon structure to gain such a stranglehold. As you state, unfortunately in the survey which you cited the nurses were not asked for their views. The time is now overdue to rectify this sad omission. The consultants, too, need to be included. Even at this late hour is it too much to hope that all is not yet lost?I am, etc.,

Cawthorne,

A. G. BUTTERS

near Barnsley

SIR,-As one of those who have previously expressed concern about the effect that the new structure is having on nursing care and recruitment, I was heartened to read your leading article (27 October, p. 186).

The best ward sisters with whom I have worked are now all reluctantly abandoning patient care for what is called administration as if that were not a ward sister's main responsibility) not because they wish to retire from the active practice of their chosen profession but because they wish to ensure an adequate pension, quite apart from finding it a humiliation to come under the command of juniors with less experience who have been promoted over their heads.

May I reiterate that the only way out of the present situation is to increase the pay of ward sisters to a level commensurate with the strain involved in, and the skills required for, this most arduous of nursing responsibilities, and which in my view should be comparable to that of the consultants with whom they work? Girls entering nursing could then look forward to rela ive affluence in later life commensurate with their qualifications and length of service, while our nursing officers would not be tempted to desert the front line for jobs on the staff.

What has happened to our sister profession could also happen to medicine; already, for instance, the potential maximum earnings of medical administrators are higher than for those who devote their lives to clinical care, research, or teaching. The best comment on such a state of affairs is in Solzhenitsyn's Cancer Ward ${ }^{1}$.-I am, etc.,

JOHN Davis

University Department of Child Health,

St. Mary's Hospital,

Manchester

Solzhenitsyn, A. I., Cancer Ward, London, Bodley Head.

\section{Monkeys for Research}

SIR,-I think that your leading article "Monkeys for Research" (14 July p. 64) calls for a comment, not because its statements are wrong, but because they are incomplete. The situation of primates and the problems of their use in research have been treated in very one-sided way.

It is correct that most of the imported primates are in poor condition, if alive at all, when they arrive at their destination, that more than $20 \%$ of the animals die in the first few months during the conditioning period, and that most of the animals are infected with parasites, bacteria, or viruses and have reduced resistance to infection owing to the "stress" caused by capturing and transportation. Yet one important fact has not been mentioned. The loss inflicted upon the wild primate populations is nor only the sum of the animals actually used in research centres plus approximately one-quarter more lost during the conditioning period; it is much higher. During most capturing actions some animals are killed on the spot accidentally or deliberately, and a high percentage of animals falls victim to inadeouate keeping conditions between capture and transportation and during transport itself, which is very often organized in a most deplorable way. It has been calculared that the losses amount to about nine individuals for every one which eventually arrives at its destination. This is still not the whole balance; in the wild populations the remaining social urits may be reduced and damaged so much by the capturing activities that they suffer additional losses or are unable to recover at all.

Now let me come to my main criticism. The article is concerned with the difficulties 